\title{
Preparation for the next major incident: are we ready?
}

\author{
K Wong, P S Turner, A Boppana, Z Nugent, T Coltman, T D A Cosker, S E Blagg
}

Emerg Med J 2006;23:709-712. doi: 10.1136/emj.2005.034025

\begin{abstract}
Background: In 1996, Carley and Mackway-Jones examined British hospital's readiness for a major incident. In the light of recent terrorist events in London, our group has revisited the issue and conducted a telephone survey of relevant parties to investigate whether the situation has changed almost 10 years on.

Materials and Methods: A proforma was devised, and registrars in anaesthesia, accident and emergency medicine, general surgery and trauma and orthopaedics were telephoned in trauma units across the UK and questioned about their readiness to respond to a major incident. Major incident co-ordinators for each of the units were contacted, and their planning, readiness, training opportunities, and recent rehearsals were assessed.

Results: A total of 179 registrars were contacted in 34 different units throughout Britain. One hundred and forty four responses were obtained. Sixty eight registrars (47\%) had not read any of their hospitals major incident plan. Only 77 (54\%) of the registrars questioned felt confident in the knowledge of their specific role during a major incident. Major incident co-ordinators were contacted at 34 hospitals, and 17 responses obtained. It was remarkably difficult to achieve even that level of response. Rehearsal of major incident plans varied widely between hospitals with $82 \%$ of hospitals having practised within the past five years but only $35 \%$ were planning for a rehearsal in the next twelve months. $25 \%$ of hospitals that responded did not hold any teaching on major incident planning at their introduction sessions for junior and middle grade doctors. Limitations to improvement of major incident planning included: lack of funds, lack of a designated full-time major incident co-ordinator, and lack of technology. There was no significant difference between units within London and those in other regions.

Discussion: Preparedness for major incidents in the UK remains poor 10 years after Carley and Mackway-Jones examined the issue. Effective major incident plans require forethought, organisation, briefing of relevant staff and regular rehearsal. Increased resources should be provided for this at a local level and more regular rehearsals undertaken to ensure our preparedness for future major incidents.
\end{abstract}

\footnotetext{
A
} major incident is an emergency (including acts of terrorism) that requires the implementation of special arrangements by one or all of the emergency services and will generally include the involvement, either directly or indirectly, of large numbers of people. ${ }^{1}$ A major incident plan (MIP) is designed to summon the right people and services to both the incident and the receiving hospital in order to maximise resources and ensure that the right people are in the right place at the right time.

In 1996, Carley and Mackway-Jones ${ }^{2}$ examined UK hospitals' readiness for a major incident and found fundamental problems in planning. Only $4 \%$ of hospital emergency plans were fully compliant with health services' guidelines. Previous studies have also highlighted lack of training experience and confidence among middle-grade staff in a projected major incident situation. ${ }^{34}$

Following the tragic events of the London bombings on 7 July 2005, during which 56 people lost their lives, our unit determined to re-evaluate the readiness of hospitals throughout the UK for the next major incident, and assess whether the relatively poor situation identified 10 years ago had changed.

Not only is readiness for a major incident an important part of any hospital's general management plan, it is also a legal requirement. ${ }^{5}$ The principal requirement of the Civil Contingencies Act, ${ }^{6}$ which came into force in November 2005 , is that comprehensive emergency plans are maintained at a local level to ensure that acute hospital trusts can continue to perform their functions in the event of a major emergency, so far as is reasonably practicable. Trusts are required to regularly update and revise their emergency plans, train appropriate staff and perform regular exercises. In order to fulfil these duties, it is essential that emergency planning is integral to normal governance and management processes.

In addition to these requirements, guidelines issued by the Emergency Preparedness Division of the Department of Health $^{5}$ and the Health Care Standards Unit (Core Standard $24)^{7}$ require that all members of staff involved: understand the roles they are to fulfil in the event of a major incident; have the necessary competencies to fulfil those roles; and have received appropriate training.

Following the bombings, it was our feeling that while the main London hospitals were in a good to reasonable state of readiness, this might not be the case in regional units. Because the Home Office regards all UK cities as potential targets for terrorist activity, this has particular relevance. It is also important to be prepared for other major incidents such as aircraft disasters and explosions (which may occur in any geographical location), and it was therefore felt appropriate to undertake a current review.

\section{METHODS}

Hospital emergency departments receiving more than 30000 patients a year were identified from the Department of Health's hospital activity status. ${ }^{8}$ Acute receiving hospitals were chosen at random from a selection of the most populated cities ${ }^{9}$ to create a wide geographical selection of hospitals throughout the UK (table 2). A standardised questionnaire was created (fig 1) and was designed to take a very short period of time to complete and therefore maximise responses from the subject group. On-call registrars in trauma and orthopaedic surgery, general surgery, anaesthetics and emergency medicine were contacted (all of whom are expected to take a lead-role in any major incident) "on site" during the twilight hours, and the telephone survey conducted. If the identified doctor was too busy to undertake the questionnaire initially, one further attempt was made at a

Abbreviation: MIP, major incident plan. 
Table 1 Results of telephone survey based upon speciality

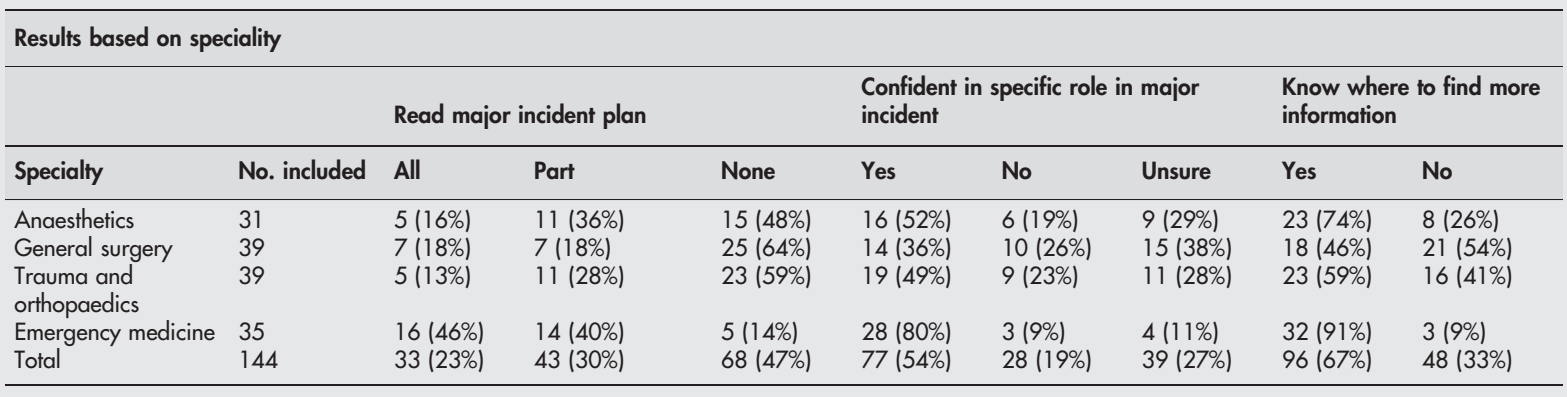

time suggested by the doctor concerned. Results were collected on the proformas and input into Microsoft Excel spreadsheets for analysis (see table 1). The senior authors supervised the collection of data to ensure uniformity of both questioning and recording. For those hospitals contacted, an attempt was also made to contact the hospital major incident coordinator, identified via the hospital switchboard. Their planning, readiness, training opportunities and recent rehearsals were assessed and the data collected by a second standardised questionnaire (table 3 ).

\section{RESULTS}

A total of 179 registrars were contacted in 34 different units throughout the UK. One hundred and forty four (80\%) of the registrars contacted consented to taking part in the survey, while the remaining $35(20 \%)$ registrars were either unable or unwilling to take part. Only $33(23 \%)$ of those taking part had read the entire MIP for the hospital at which they were based, $43(30 \%)$ had read the part relating to their specific specialty and $68(47 \%)$ had not read any of their hospital's MIP. Only $77(54 \%)$ of the registrars questioned felt confident in the knowledge of their specific role in a major incident situation. However, 96 (67\%) knew where more information concerning their role in a major incident could be found.

The breakdown of registrars in each specialty in shown in table 1 . Of the registrars based in emergency medicine, 30 $(86 \%)$ had read part, or all, of their hospital's MIP, and 28 $(80 \%)$ expressed confidence in their specific role should a MIP be activated. Only $14(36 \%)$ of the general surgical registrars interviewed had read any part of their hospital's MIP, with 21 (54\%) registrars unsure as to where more information could be obtained.

Of the registrars based in emergency medicine in London, 9 $(82 \%)$ felt confident in their role in a proposed major incident situation, with the same number having read part, or all, of their MIP. Twenty one (88\%) emergency medicine registrars based outside of London had read their hospital's MIP with $20(83 \%)$ feeling confident in their role should a MIP be activated. Only $25(49 \%)$ registrars from other specialties based in London had read their MIP, with only 29 (57\%) confident of their specific role in a major incident situation. Of registrars based in other specialties outside of London, 21 (36\%) had read their hospital's MIP, with 35 (60\%) confident of their role.

Of the 76 middle-grade staff who read their MIP, 62 (82\%) felt confident in their roles. Of those who did not read their MIP, only 31 of $68(46 \%)$ felt confident. We acknowledge that our questionnaire was not detailed enough to correlate whether having an orientation session and having rehearsed practice runs led to increase confidence of middle-grade staff.

Of the 34 major incident coordinators contacted, only 17 $(50 \%)$ responses were obtained; 4 (11\%) of the coordinators refused to take part in the survey. It was remarkably difficult to obtain responses in many cases despite persistent effort on the part of our researchers. Fourteen (82\%) of the hospitals surveyed across the UK had activated their MIP in response to a real situation within the past 5 years; with a range of 2-5 real major incident situations per hospital. The same number of hospitals had held full-scale rehearsals of their MIP within the past 5 years. The number of rehearsals varied from once every 5 years, to six-monthly exercises, although the majority held rehearsals every $1-2$ years. Six $(35 \%)$ of the hospitals surveyed were planning to do a full-scale rehearsal of their MIP in the near future. Four $(24 \%)$ hospitals did not provide any teaching of major incident planning at their introduction sessions for junior and middle-grade doctors.

Lack of funding $(53 \%)$, lack of a designated person who had sufficient time to deal with major incident training (47\%) and lack of technology leading to inefficient communications $(29 \%)$ were cited as problems in many units (table 3).

There was no significant difference between units within London and those in other regions; both in doctor's knowledge of the MIP and recent rehearsals of that plan. However, registrars based in emergency medicine had received more training about their hospital's MIP, and felt more confident

Table 2 Results of telephone survey based on location

\begin{tabular}{|c|c|c|c|c|c|c|c|c|c|}
\hline \multicolumn{10}{|l|}{ Results based on location } \\
\hline \multirow[b]{2}{*}{ Location } & \multirow[b]{2}{*}{ No Included } & \multicolumn{3}{|c|}{ Read major incident plan } & \multicolumn{3}{|c|}{$\begin{array}{l}\text { Confident in specific role in major } \\
\text { incident }\end{array}$} & \multicolumn{2}{|c|}{$\begin{array}{l}\text { Know where to find more } \\
\text { information }\end{array}$} \\
\hline & & All & Part & None & Yes & No & Unsure & Yes & No \\
\hline Central London & 62 & $18(29 \%)$ & $16(26 \%)$ & $28(45 \%)$ & $33(53 \%)$ & $15(24 \%)$ & $14(23 \%)$ & $43(69 \%)$ & $19(31 \%)$ \\
\hline $\begin{array}{l}\text { Outside London (includes } \\
\text { Birmingham, Manchester, } \\
\text { Edinburgh, Aberdeen, } \\
\text { Glasgow, outer London) }\end{array}$ & 82 & $15(18 \%)$ & $27(33 \%)$ & $40(49 \%)$ & 44 (54\%) & $13(16 \%)$ & $25(30 \%)$ & $53(65 \%)$ & $29(35 \%)$ \\
\hline Total & 144 & $33(23 \%)$ & $43(30 \%)$ & $68(47 \%)$ & $77(54 \%)$ & $28(19 \%)$ & $39(27 \%)$ & $96(67 \%)$ & $48(33 \%)$ \\
\hline
\end{tabular}


Table 3 Questionnaire and results of survey from major incidents coordinators

\begin{tabular}{|c|c|c|c|c|}
\hline & Yes & No & Refused & $\begin{array}{l}\text { No responses despite several attempts } \\
\text { via telephone and/or emails }\end{array}$ \\
\hline $\begin{array}{l}\text { How many real trials in past } 5 \text { years or as far } \\
\text { back as you can remember }\end{array}$ & 14-ranging from 2-5 & 3 & 4 & 13 \\
\hline $\begin{array}{l}\text { How many practice runs in past } 5 \text { years - } \\
\text { full blown }\end{array}$ & $\begin{array}{l}14 \text {-ranging from } 2 \text { yearly } \\
1 \text { in } 5 \text { years }\end{array}$ & 3 & & \\
\hline Are you planning any trials? & 6 & 11 & & \\
\hline Presentation at introduction for new juniors & 13 & 4 & & \\
\hline Regular meetings for update of plan & $\begin{array}{l}\text { 16-ranging from monthly } \\
\text { to yearly meetings }\end{array}$ & 1 & & \\
\hline \multirow{3}{*}{$\begin{array}{l}\text { Were any mistakes identified in last trial or } \\
\text { real practice? } \\
\text { What is the limiting factor for not having trials } \\
\text { or regular meetings or not being able to fix } \\
\text { known problems in major incident plans: } \\
\text { funding, time, lack of person in charge of major } \\
\text { incident planning,communition/technology? }\end{array}$} & 13 & & & \\
\hline & 9 No budget & & & \\
\hline & $\begin{array}{l}8 \text { No set person } \\
5 \text { Not necessary technology } \\
\text { exp communication } \\
1 \text { Low on list of priority } \\
6 \text { Lack of time }\end{array}$ & & & \\
\hline
\end{tabular}

of the role required of them, compared with registrars based in other specialties.

\section{DISCUSSION}

Events of 11 September 2001 in New York, 12 October 2002 in Bali and 7 July 2005 in London have focused the minds of Western nations with regard to their susceptibility of experiencing a major terrorist atrocity, and their readiness to deal with such an event.

Each such terrorist event typically occurs totally unexpectedly and is frequently accompanied by public panic and unrest, transportation failure and disruption of major infrastructure. It is therefore vital that units expecting to receive large numbers of casualties are both ready and well rehearsed to deal with a major incident if it occurs. It is

1) What would you do if you suddenly received a large influx of patients to $A$ and $E$ with acute traumatic injuries? (For example 30-40 patients)

\begin{tabular}{|l|l|l|l|l|}
\hline $\begin{array}{l}\text { Activate } \\
\text { internal major } \\
\text { incident plan }\end{array}$ & $\begin{array}{l}\text { Call } \\
\text { Consultant on } \\
\text { call }\end{array}$ & $\begin{array}{l}\text { Do nothing } \\
\text { and continue } \\
\text { working }\end{array}$ & $\begin{array}{l}\text { Recruit other } \\
\text { team members }\end{array}$ & Other \\
\hline & & & & \\
\hline
\end{tabular}

2) Have you read your hospital's major incident plan?

\begin{tabular}{|l|l|l|l|l|}
\hline Read all & Read parts & $\begin{array}{l}\text { Read part } \\
\text { relevant to } \\
\text { position }\end{array}$ & Nothing & \\
\hline & & & & \\
\hline
\end{tabular}

3) Do you know where you can access your hospital's major incident plan guidelines?

\begin{tabular}{|c|l|l|l|l|}
\hline Yes & No & $\begin{array}{l}\text { I think so but } \\
\text { not sure }\end{array}$ & $\begin{array}{l}\text { I think so but } \\
\text { pretty sure }\end{array}$ & \\
\hline & & & & \\
\hline
\end{tabular}

4) Do you know what role you would play if a major incident plan came into effect whilst you were on call?

\begin{tabular}{|l|l|l|l|l|}
\hline Definite yes & Definite no & $\begin{array}{l}\text { I think so but } \\
\text { not sure }\end{array}$ & $\begin{array}{l}\text { I think so but } \\
\text { pretty sure }\end{array}$ & \\
\hline & & & & \\
\hline
\end{tabular}

Figure 1 Proforma used to question middle-grade staff on their knowledge of major incident plans anticipated that although it is possible for any general hospital member of staff to activate the hospital MIP, it would usually be most appropriate for that member of staff to liaise with their colleagues in the emergency department, since this is where casualties will arrive.

Brennan et $a l^{3}$ were among the first to identify lack of awareness of major incident planning in middle-grade staff in the South East Thames Region in 1994. Only 39\% of doctors were found to have received MIP-related literature and less than a third had attended an MIP orientation session. During that time $88 \%$ of hospitals surveyed had apparently held training exercises.

In 1996, Carley and Mackway-Jones ${ }^{2}$ went on to identify fundamental problems with MIPs in the 142 hospitals that they surveyed. Their conclusion was that only $4 \%$ of hospitals had plans fully compliant with health services' guidelines. A study in Wessex in 2002 showed that only $45 \%$ of specialist registrars felt confident of their role should they be asked to participate in a major incident. ${ }^{4}$

The 7 July bombings resulted in the activation of MIPs in many London hospitals. This is in addition to an increasing regularity with which plans are activated either for false alerts or failed terrorist attempts. It is highly likely that British hospitals will face an increasing number of major incidents in the future.

We aimed to evaluate the preparedness of middle-grade staff along with their hospitals for the next major incident. We conclude that there remains significant deficiencies in the awareness of middle-grade staff of their roles should a major incident occur. Although registrars based in emergency medicine departments throughout the UK were generally better prepared for a major incident situation, there remains room for improvement. A significant lack of awareness and training is highlighted among registrars not based in emergency medicine, who will be expected to play a significant role in the management of patients should a MIP be activated.

On a more positive note, a significant number of hospitals have recently implemented a presentation on major incidents at the induction sessions for junior and middle-grade doctors. Lack of funds and a designated person who has enough time and resources available were cited as major difficulties in repairing known deficiencies in MIPs and training, and this is ultimately reflected in the persisting deficiencies in staff who will be expected to play significant roles in these situations. 
Preparedness requires meticulous planning, extensive education and regular rehearsal and review if it is to be effective ${ }^{10}$ Remarkably, even though major incident planning is recognised as a priority for many units, most are still struggling to implement changes to result in actual "on the ground" improvements. Because hospital doctors rotate through different hospitals, MIPs should be more standardised between hospitals. A comprehensive induction for all medical and paramedical staff as well as more regular rehearsal appears to be the key to success so all members of the team feel ready to respond. It is also recommended that doctors take the initiative to find out their hospital's MIP and familiarise themselves with their indicated roles.

Our study suggests that there is still considerable room for improvement in British hospitals' readiness for a major incident, and that the situation has changed little since similar studies were done from 1994 to 2002. Urgent investment, education and rehearsal of MIPs is recommended.

\section{Authors' affiliations}

K Wong, P S Turner, A Boppana, T Coltman, T D A Cosker, S E Blagg,

Wycombe Hospital, South Buckinghamshire NHS Trust,

Buckinghamshire, UK

Z Nugent, North Middlesex University Hospital, London, UK

Competing interests: None.
Correspondence to: Tom Cosker, Wycombe Hospital, South

Buckinghamshire NHS Trust, Queen Alexandra Road, High Wycombe, Buckinghamshire HP1 1 2TT UK; tomcosker@hotmail.com

Accepted for publication 11 June 2006

\section{REFERENCES}

1 London Emergency Services Liaison Panel. Available at http:// www.leslp.gov.uk/frames.htm (accessed 18 Dec 2005).

2 Carley S, Mackway-Jones K. Are British hospitals ready for the next major incident? Analysis of hospital major incident plans. BMJ 1996;313:1242-3.

3 Brennan L, Sage FJ, Simpson A. Major incident planning in South East Thames Region: a survey of medical staff awareness and training. J Accid Emerg Med 1994;11:85-9.

4 Madge SN, Kersey JP, Murray G, et al. Are we training junior doctors to respond to major incidents? A survey of doctors in the Wessex region. Emerg Med J 2004;21:577-9.

5 HM Government. Emergency preparedness: guidance on part 1 of the Civil Contingencies Act 2004, its associated regulations and non-statutory arrangements. Available at http://www.ukresilience.info laccessed 9 Dec 2005).

6 Civil Contingencies Act 2004. London: HMSO, Available at http:// www.opsi.gov.uk/acts/acts2004/20040036.htm (accessed 23 Nov 2005).

7 Department of Health. Standards for better health. Available at http:// www.dh.gov.uk (accessed 18 May 2006).

8 Department of Health. Hospital activity statistics. London: NHS Confederation, 2006, Available at http://www.performance.doh.gov.uk/hospitalactivity/ data_requests/a_and_e_attendances.htm (accessed 10 Sep 2005).

9 City Mayors statistics. The UK's 200 largest towns, cities and districts. Available at http://www.citymayors.com/gratis/uk_topcities.html (accessed 10 Sep 2005).

10 National Audit Office. Facing the challenge: NHS emergency planning in England. London: National Audit Office, 2002, Available at http://www.nao.gov.uk (accessed 5 Oct 2005). 